\title{
THE FORMAL EQUATIONS OF THE LOW LATITUDE LOWER IONOSPHERE AND THEIR APPLICATIONS
}

\author{
Carlos José Zamlutti \\ Recebido em 15 setembro, 2004 / Aceito em 03 agosto, 2005 \\ Received on September 15, 2004 / Accepted on August 03, 2005
}

\begin{abstract}
The work presents two applications of the formal equations governing the behavior of the low latitude lower ionosphere comprised into a unique set. This set can be used for modeling purposes as well as to help the interpretation of most of the phenomena related to equatorial and low latitude dynamics. Furthermore coupling processes can also be analyzed combining ion transport and ion molecule chemistry to explain the connection between the circulation of the lower and upper portions of the range $100-200 \mathrm{~km}$ of altitude. Here the uses and interpretation of these equations to explain some controversial and intriguing questions as to the behavior of phenomena like sporadic $\mathrm{E}$ and intermediate layers are explored. It is shown, in particular, that the proposed set of equations is quite convenient in this respect.
\end{abstract}

Keywords: Ion model, sporadic E, intermediate layers, low latitude circulation.

RESUMO. Este trabalho apresenta duas aplicações das equações formais que governam o comportamento da baixa ionosfera nas latitudes baixas compreendidas em um conjunto de equações acopladas. Este conjunto pode ser usado para propósito de modelagem como também para ajudar na interpretação da maioria dos fenômenos relacionados com a dinâmica das regiões: equatorial e de latitudes baixas. Além disto processos de acoplamento podem também ser analisados combinando-se a química e transporte dos íons para explicar a conexão entre as circulações das porções alta e baixa do intervalo de alturas 100-200 km. Aqui 0 uso e interpretação dessas equações são explorados para explicar algumas questões intrigantes e controvertidas quanto ao comportamento de fenômenos como as camadas E esporádica e intermediária. É mostrado, em particular, que o conjunto de equações propostas é muito conveniente neste sentido.

Palavras-chave: Modelo ionosférico, camada E esporádica, camadas intermediárias, circulação nas baixas latitudes. 


\section{INTRODUCTION}

The ionosphere and its regions have been widely studied and modeled as can be appreciated in the textbooks by Schunk \& Nagy (2000) or Kelley (1992) and also in numerous reviews (e.g. Schunk, 1983; Nagy \& Schunk, 1987; Sojka, 1989 etc.) in the last decades. Notwithstanding this fact a simple model which can be employed for the low latitude lower ionosphere, to explain at a time the climatological and weather aspects, was adjusted by Zamlutti (2003) to comprise in one unified approach the several models employed to explain the different phenomena like sporadic $E$ layers and spread $F$. Here we recall it with focus on two of its applications. Experimental evidence of the need of such a model was presented in Mathews et al. (2001). General guidelines for it are found as "weakly ionized plasma" in Schunk \& Nagy (2000) or "equatorial zone electrodynamics" in Kelley (1992).

The lower ionosphere (100-200 km of altitude) is characterized as being a thermal equilibrium region due to the large number of collisions of charged with neutral particles. The reader may identify the considered region as "weakly ionized plasma" in Schunk \& Nagy (2000) or "equatorial zone" in Kelley (1992). Under these conditions the equation of state can be used to replace the equation for conservation of energy. This approximation holds satisfactory during nighttime for the entire range of altitudes and during daytime only up to $160 \mathrm{~km}$; above this altitude other considerations will be added later on. Hence a simplified system consisting of the continuity and momentum equations can be employed to describe the behavior of the charged particles. One gets:

$$
\begin{gathered}
d n / d t+n \nabla \cdot \underline{u}=\delta n \\
n d \mathbf{u} / d t+m^{-1} \nabla p-n \mathbf{a}=\delta \mathbf{M} .
\end{gathered}
$$

where $m$ is the mass, $\mathbf{u}$ the flow velocity and $\mathbf{a}$ the acceleration imposed by external fields. Here $p$ stands for pressure and $n$ is the number density, which are connected by the equation of state $p=n k T$ with $k$ the Boltzmann's constant and $T$ the absolute kinetic temperature. The right hand side (RHS) expresses the rate of change in the parameters (density, $n$; momentum, $\mathbf{M}$ ) produced by collisions and production and loss mechanisms. Reactive collisions are the loss mechanism for the density equation (1) and elastic collisions prevail as the loss mechanism for the momentum equation (2). This result can be easily inferred from the modeling equations by Bristow \& Watkins (1991) or Zamlutti (1998). Subscripts will be attached to the parameter symbols to represent neutrals $n$, electrons, $e$, or ions, $i$.

Charged particles are acted upon by gravity, electric and magnetic fields besides undergoing the action of Coriolis and centri- petal forces. The overall acceleration is expressed as:

$$
\mathbf{a}=\mathbf{g}^{*}+\left(q^{*} / m\right)(\mathbf{E}+\mathbf{u} \times \mathbf{B})
$$

with

$$
\mathbf{g}^{*}=\mathbf{g}+2 \omega^{*} \times \mathbf{u}+\omega^{*} \times \omega^{*} \times \mathbf{R}
$$

where $\mathbf{g}^{*}$ is the acceleration due to mechanical forces; $\mathbf{g}$ is the acceleration of gravity, $\omega^{*}$ is the earth's angular velocity and $\mathbf{R}$ is the geocentric distance. The vector $\omega^{*}$ is directed towards the geographic north. Here $q^{*}$ is the particle charge, $\mathbf{E}$ is the electric field and $B$ the geomagnetic field.

Employing (3) in (2) and considering the momentum transfer elastic collision term one gets the fundamental equation for the balance of forces in the lower ionosphere. The interaction of the several forces in (2) gives rise to many interesting particular situations, mainly near the magnetic equator, known as weather phenomena. To explain these phenomena several approaches were proposed depending on the considered terms of the full equation (2). In particular Bristow \& Watkins (1991) presented a trapping model based on (2) and using $\delta n=0$ in (1) but released the constraint of thermal equilibrium. Helmer et al. (1998) proposed a one dimensional steady model of meteoric iron using a complete description of $\delta n$ in (1); Osterman et al. (1994); Carter \& Forbes (1999) proposed complete models unified by Zamlutti (2003) and finally McNeil et al. (1996) defended the line of simple models accounting for an appropriate $\delta n$ in (1) but discarding some contributions in (2). The most complete models were presented by Osterman et al. (1994); Carter \& Forbes (1999) and Zamlutti (2003) who tried to overcome the shortcomings of earlier approaches discussed in Mathews (1998). In particular it was pointed out that a strong coupling involving the equatorial lower ionospheric features exists as discussed by Mathews et al. (2001).

In this work the general equations of Zamlutti (2003) who comprises in a unified treatment the major points of both Osterman et al. (1994) and Carter \& Forbes (1999) are analyzed to examine the interrelationship among the several equatorial lower ionosphere phenomena. The peculiar connection between the intermediate and sporadic $E$ layer is explained in terms of the quite effective charge transfer chemical reaction between molecular and metallic species (Murad, 1978). The work is organized starting with the fundamental equations and basic assumption employed in their derivation in Section 2. Two weather phenomena are considered in Section 3, namely sporadic E-layers and intermediate layers. 


\section{FUNDAMENTAL EQUATIONS}

The approach to be presented next can be considered a half way between the generality of Schunk \& Nagy (2000) and the special of Kelley (1992).

As for Zamlutti (2003) the equatorial and low latitude ionosphere regular behavior can be described as:

$$
d n / d t+n \nabla \cdot \mathbf{u}=(\delta n)_{p}-v_{r} n
$$

where $(\delta n)_{p}$ stands for production rate of ionization and $v_{r} n$ accounts for ionization loss. The symbol $v_{r}$ represents recombination rate.

Here:

$$
\mathbf{u}=\underline{\underline{\gamma}} \cdot \mathbf{F}
$$

with

$$
\mathbf{F}=m \mathbf{g}-n^{-1} \nabla p+q^{*} \mathbf{E}+\mu_{j} v_{j} \mathbf{u}_{j}
$$

and the mobility tensor in geomagnetic coordinates:

$$
\underline{\underline{\gamma}}=\left[\begin{array}{lll}
\gamma_{0} & 0 & 0 \\
0 & \gamma_{1} & -\gamma_{2} \\
0 & \gamma_{2} & \gamma_{1}
\end{array}\right]
$$

where

$$
\begin{aligned}
& \gamma_{0}=\left(\mu_{j} v_{j}\right)^{-1}=1 /\left(B q^{*} r\right) \\
& \gamma_{1}=\gamma_{0}\left[r^{2} /\left(r^{2}+1\right)\right]\left(1 / B q^{*}\right)\left[r^{2} /\left(r^{2}+1\right)\right] \\
& \gamma_{2}=\gamma_{0}\left[r /\left(r^{2}+1\right)\right] \\
&=\left(1 / B q^{*}\right)\left[1 /\left(r^{2}+1\right)\right] \\
& r=\mu_{j} v_{j} / m \Omega
\end{aligned}
$$

Here $\Omega=q^{*} B / m$ is the cyclotron frequency, $\mu_{j}$ is the reduced mass between the incident and colliding particle, $v_{j}$ is the elastic collision frequency and subscript $j$ denotes interacting species. The $\gamma$ quantities are called mobility and expressed in geomagnetic coordinates with subscript 0 along the geomagnetic field direction, subscript 1 normal to the plane of the geomagnetic field lines and subscript 2 normal to the geomagnetic field in the plane of the field lines. Moreover, $\gamma_{0}$ is named direct, $\gamma_{1}$ Pedersen and $\gamma_{2}$ Hall.

Equation (6) was established under the constraint of a steady state velocity field. This is particularly true for the terrestrial lower ionosphere in the range $100-200 \mathrm{~km}$ of altitude, where tidal velocities predominate. In this case the relations:

$$
\partial \mathbf{u} / \partial t=\omega \tilde{\mathbf{u}}<<\mathbf{g}
$$

$$
\mathbf{u} \cdot \nabla \mathbf{u}<<(n m)^{-1} \nabla p
$$

hold valid even in the situation of gravity waves with periods as small as $15 \mathrm{~min}$ and amplitude $\tilde{u}=150 \mathrm{~m} / \mathrm{sec}$ (see Zamlutti, 1975). Here $\omega$ is the angular velocity of the oscillatory behavior. Constraint a) restricts to subsonic flows and $b$ implies the diffusion approximation (see Schunk \& Nagy, 2000). Moreover, limitation a) excludes high frequency plasma wave phenomena. To overcome this limitation one must simply add $\omega$ to the value of $v_{j}$ in Equations (8) and (11). The predominance of tidal velocities does not mean that electric fields are absent, since they participate in Equation (7).

The tensor $\underline{\underline{\gamma}}$ as expressed before refers also to a geographic coordinate system coincident with the geomagnetic one. The situation occurs approximately at the Earth's equator if we disregard the small magnetic declination. To get (7) valid for geographic coordinates in the low-latitude region Zamlutti (2003) showed that a similarity transformation is necessary in $\underline{\underline{\gamma}}$ such that:

$$
\underline{\underline{\gamma}}^{(\theta)}=\underline{\underline{G}}^{t}(I) \cdot \underline{\underline{\gamma}} \cdot \underline{\underline{G}}(I)
$$

where $\theta$ stands for the geographic latitude, $I$ for the dip angle superscript $t$ for transpose. The matrix $\underline{\underline{G}}(I)$ is given by:

$$
\underline{\underline{G}}=\left[\begin{array}{lll}
\cos I & 0 & \sin I \\
0 & 1 & 0 \\
-\sin I & 0 & \cos I
\end{array}\right]
$$

Under these circumstances the low latitude $\underline{\underline{\gamma}}$ components become:

$$
\begin{aligned}
& \gamma_{11}=\gamma_{0} \cos ^{2} I+\gamma_{1} \sin ^{2} I \\
& \gamma_{22}=\gamma_{1} \\
& \gamma_{33}=\gamma_{0} \sin ^{2} I+\gamma_{1} \cos ^{2} I \\
& \gamma_{12}=-\gamma_{21}=-\gamma_{2} \sin I \\
& \gamma_{13}=\gamma_{31}=\left(\gamma_{0}-\gamma_{1}\right) \sin I \cos I \\
& \gamma_{23}=-\gamma_{32}=-\gamma_{2} \cos I
\end{aligned}
$$

These results are in agreement with those by Forbes (1981), and the same approach is employed by Kelley (1992) for this matter.

The dip angle is related to the geographic latitude by the expression $\tan I=+2 \tan \theta$ and the magnetic field intensity follows the inverse cubic law dependence relative to the radial distance from the center of Earth, namely $B / B_{0}\left(R_{0} / R\right)^{3}$, with $R$ the radial distance (see Rishbeth \& Garriott, 1969).

The reader may not get the misleading impression that (1) and (2) hold through in the range 100-200 km of altitude, for the 
entire day. As a matter of fact during daylight hours the electron temperature departs from the ion and neutral temperatures above $160 \mathrm{~km}$ of altitude. This occurs due to the recoil energy acquired by the photoelectrons during the photo ionization process (see Schunk, 1983), which is transferred to neutrals by reactive collisions exciting rotational and vibrational states and to thermal electrons through collisional transfer (see Zamlutti, 1997; 1998). The ions also acquire energy from photoelectrons through collisional interaction storing it in the form of electronic excitation (Zamlutti, 1997). Then, from Zamlutti (1998), one can write for daylight hours the energy equation in the form:

$$
\nabla \cdot \mathbf{q}=\delta \varepsilon
$$

where $\mathbf{q}$ stands for the heat flow vector and the RHS denotes energy variation due to production and loss processes. The heat flow is related to the pressure by:

$$
q=\zeta \nabla[p /(n m)]
$$

where $\zeta=(25 / 8) m^{-1}\left(p / v_{j}\right)$, according to Schunk (1975). The energy variation due to a reactive process is given by:

$$
\delta \varepsilon=\int_{\lambda} \phi(\lambda)\left(\delta E_{\lambda}\right)_{p} d \lambda-n_{e} k T_{e},
$$

where $\phi(\lambda)$ is the solar radiation flux,

$$
\left(\delta E_{\lambda}\right)_{p}=\left[(h c / \lambda)-\sum_{j}\left(U_{i}\right)_{j}\right] n_{j} S_{j}^{*}
$$

with $h$ is the Planck's constant, $\lambda$ the wavelength of the incident radiation, $S_{j}^{*}$, and $\left(U_{i}\right)_{j}$ are the ionization cross-section and energy of particle species $j$ and $c$ the speed of the light. Here no account of excitation of metastable species was taken (see Zamlutti, 1997) and photoelectrons were assumed to deliver their energy locally. Schunk (1983) estimate the value of $\delta E$ vs altitude. Another alternative to evaluate the electron temperature is to resort to empirical models as that of Brace \& Theis (1978):

$$
T_{e}=a_{1}+\left(a_{2} h+a_{3}\right) \exp \left(a_{4} h+a_{5} n_{i}+a_{6} h n_{i}\right)
$$

where

$T_{e}$ is expressed in units of ${ }^{O} \mathrm{~K}$

$n_{i}$ is in units of $\mathrm{cm}^{3}$

$h$ is in kilometer with

$$
\begin{aligned}
& a_{1}=1.051 \times 10^{3} \\
& a_{2}=1.707 \times 10^{1} \\
& a_{3}=-2.746 \times 10^{3} \\
& a_{4}=-5.122 \times 10^{-4} \\
& a_{5}=6.094 \times 10^{-6} \\
& a_{6}=-3.353 \times 10^{-8}
\end{aligned}
$$

\section{EQUATORIAL AND LOW LATITUDE WEATHER PHENO- MENA}

The traditional or climatological solution for (5) results from the chemical balance between production and loss terms, which yields the well known idealized Chapman layer.

$$
\begin{gathered}
n_{e}=\left(P_{m} / v_{r}\right)^{1 / 2} \\
\exp \left\{1 / 2\left[1-\frac{z-z_{0}}{H}-\exp \left(\frac{z_{0}-z}{H}\right) \sec \chi\right]\right\}
\end{gathered}
$$

(Rishbeth \& Garriott, 1969). Here $P_{m}$ denotes the peak production value, $v_{r}$ the recombination rate, $H$ the neutral scale height, $z$ the altitude and $\chi$ the zenith angle. While (19) holds satisfactory for daytime, it must require adjustments to account for the importance of the transport term $\underline{u} \cdot \nabla n$ during nighttime (Lanchester et al., 1989). As for (6) the balance between external forces and elastic collisional transfer predominates for ions.

Some equatorial and low latitude weather phenomena received significant attention in the last decade (Wilkinson et al., 1992; Mathews, 1998). In particular, sporadic E and intermediate layers were considered. Zamlutti (2003) included also the equatorial electrojet and spread $\mathrm{F}$ to comprise all these phenomena into a unified theoretical approach. One can distinguish two sorts of phenomena:

a) Enhanced layers resulting from a small value of $v_{r}$ in (19);

b) Layers with peculiar behavior or amplified amount of wavelike disturbances produced by special features of the system (5) and (6).

The first class includes the sporadic E metallic layers and the molecular nighttime intermediate layers. The second one contains the equatorial electrojet and also $\mathrm{E}$ and $\mathrm{F}$ layer irregularities.

For limiting reasons we will be concerned here only with the first class of phenomena, for which the most important aspects are the chemical behavior in (5) and the confinement condition 
applied to (6), as for Zamlutti (2003). Therefore in our continuity equation (5) the LHS is completely discarded based on a time scale analysis by Kane \& Gardner (1993), for metallic species.

Regarding the chemistry characteristic we will adopt the reactive treatment of Eccles \& Raitt (1992) and Zamlutti (1997). Hence the value of $\delta n$ of (1) is given by:

$$
\delta n=\sum_{a, b} k_{a, b} n_{a} n_{b}-\sum_{l} k_{l} n n_{l}
$$

where the $k$ denote: reaction rates. The first term of the RHS is represented by $(\delta n)_{p}$ in (5) and accounts not only for direct ionization but also for the ablation of meteoroids producing metal atoms and complexes and their subsequent transformations as well as charge exchange collisions (see McNeil et al., 1996; Helmer et al., 1998; Carter \& Forbes, 1999). The second term of the RHS expresses loss of ionization for which the most important case is the recombination process denoted as $v_{r} n$ in (5) and also charge transfer reactions.

Below $140 \mathrm{~km}$ sporadic layers are constituted of metallic species mainly iron (Behnke \& Vickrey, 1975; Kopp, 1997), magnesium and sodium (Kopp, 1997; Helmer et al., 1998; McNeil et al., 1996). The major source of metallic species observed in the upper mesosphere and thermosphere is the ablation of meteoroids entering into the Earth's atmosphere. Direct ionization by the solar radiation is not effective and metal ions are produced by charge exchange collisions of metal neutrals with the major molecular or atomic ions (Murad, 1978). Sometimes two steps including oxidation and molecular dissociation also produce metallic ion (McNeil et al., 1996; Murad, 1978; Helmer et al., 1998). The estimated rate constant is $k_{p}=10^{-9} \mathrm{~cm}^{3} \mathrm{~s}^{-1}$ and therefore:

$$
(\delta n)_{p}=10^{-9} n(M) n_{e}
$$

where $M$ denotes the metal specie. The corresponding time constant is $\tau_{p}=\left(k_{p} n_{e}\right)^{-1}$ which ranges from 20 minutes to $3 \mathrm{~h}$ from $135 \mathrm{~km}$ to $110 \mathrm{~km}$ of altitude, during daytime. Nighttime values exceed 20h. Even during daytime metal ionization times surpass $6 \mathrm{~h}$, below $100 \mathrm{~km}$. Regarding the loss processes the dominating mechanism above $100 \mathrm{~km}$ is recombination at a rate $k_{l}=10^{-12} \mathrm{~cm}^{3} \mathrm{~s}^{-1}$ from the same sources as above (Murad, 1978; McNeil et al., 1996 and Helmer et al., 1998). Then $v_{r}=10^{-12} n_{e}$ and thus:

$$
(\delta n)_{l}=10^{-12} n\left(M^{+}\right) n_{e}
$$

The chemical time constant $\delta_{\text {che }}=1 / v_{r}$ varies between 6 and 60 days in the range $140-80 \mathrm{~km}$ of altitude due to the above mechanism. Other processes may take place (Murad, 1978) but the long lifetime of metallic ions is unquestionable. As an example oxidation through reaction with ozone below $100 \mathrm{~km}$ may require only 3h. Helmer et al. (1998), claim that oxidation - reduction recombination processes are a more effective loss mechanism with an overall rate $k_{l}=10^{-11} \mathrm{~cm}^{3} \mathrm{~s}^{-1}$ based on Plane \& Helmer (1994) conclusions. This reduces the $80 \mathrm{~km}$ chemical time constant to $15 \mathrm{~h}$ but the $140 \mathrm{~km}$ one remains the same, because of the long time constant of the reaction $\mathrm{F}_{e}+\mathrm{O}_{2} \rightarrow \mathrm{F}_{e} \mathrm{O}_{2}$ and the transformation of $F_{e}^{+}$into $F_{e}$ by oxidation is an unstable process with time constant comparable to that of the recombination process (Plane \& Helmer, 1994). Under the condition of strict chemical equilibrium:

$$
n\left(M^{\doteqdot}\right)=10^{3} n(M)
$$

and hence metal species must be fully ionized above $100 \mathrm{~km}$. However, below this altitude it is reasonable to consider that $n\left(M^{\div}\right)=n(M)$ as posed by Granier et al. (1989) and Kopp (1997). The solution of the continuity equation for the metallic neutrals is quite involving since one must consider ablated material as a source, chemistry processes for production and loss and transport by eddy and molecular diffusion (see McNeil et al., 1996 and Helmer et al., 1998). Instead here we assume the existence of these species by means of an empirical slowly time varying profile. Following the profiles presented by observational references Zamlutti (2003) suggested two alternative empirical models for metallic iron. Here we examine his parabolic model:

$$
\left\{\begin{array}{l}
n(F e)=n_{0}\left[1-\frac{\left(h-h_{0}\right)^{2}}{H_{0}^{2}}\right] \text { for } h_{\min }<h<h_{\max } \\
n(F e)=0 \text { otherwise }
\end{array}\right.
$$

with $h_{0}=90 \mathrm{~km}, H_{0}=10 \mathrm{~km}, h_{\min }=80 \mathrm{~km}$, $h_{\max }=100 \mathrm{~km}, n_{0}=10^{3} \mathrm{~cm}^{-3}$, in the light of measurements. The total column density is about $13.3 \times 10^{8} \mathrm{~cm}^{-2}$, which is half as low as the column density of $F_{a}^{+}$(Kopp, 1997). Hence $n_{0}=2.0 \times 10^{3} \mathrm{~cm}^{-3}$ seems a more appropriate value. Helmer et al. (1998) allowed for a sinusoidal seasonal variation of $n_{0}$ by adding a term $n_{i} \cos (2 \pi t / 365)$ where $t$ is the day of the year. They employed $n_{0}=1.3 \times 10^{3} \mathrm{~cm}^{-3}$ and $n_{1}=0.7 \times 10^{3} \mathrm{~cm}^{-3}$. McNeil et al. (1996) using the complete continuity equation found results with $n_{0}=4 \times 10^{3} \mathrm{~cm}^{-3}$, $h_{0}=85 \mathrm{~km}$ for Mg. Kane \& Gardner (1993) collected nighttime data and obtained $n_{0}=1.2 \times 10^{3} \mathrm{~cm}^{-3}, n_{1}=0.6 \times$ $10^{3} \mathrm{~cm}^{-3}$, with $h_{0}=85 \mathrm{~km}$ and was a data source for Helmer et al. (1998). Thus Zamlutti (2003) profile can be improved replacing $n_{0}$ by $\left[n_{0}+n_{1} \cos [2 \pi t / 365]\right]$ with the Helmer et al. (1998) values for $n_{0}$ and $n_{1}$. 
Above $140 \mathrm{~km}$ enhanced ion layers are constituted of molecular species $\left(\mathrm{O}_{2}^{+}, \mathrm{NO}^{+}\right)$and called intermediate layers. To solve the continuity equation we investigate first on the possibility of a chemical equilibrium. Molecular ions appear at altitudes where the ion lifetime is sufficient to sustain the layer (see Mathews, 1998). To examine their characteristics we recall here the involved chemistry mechanism, in the light of the simple model of Torr et al. (1979). The molecular oxygen reactions are:

$$
\begin{cases}O+h v \rightarrow O^{+}\left({ }^{4} S\right)+e & k_{p}=1.39 \times 10^{-7} \mathrm{~s}^{-1} \\ O^{+}\left({ }^{4} S\right)+O_{2} \rightarrow O_{2}^{+}+O & k_{11}=0.55 \times 10^{-11} \mathrm{~cm}^{3} \mathrm{~s}^{-1}\left(1000^{\circ} k\right) \\ O_{2}^{+}+e \rightarrow O+O & k_{12}=0.69 \times 10^{-7} \mathrm{~cm}^{3} \mathrm{~s}^{-1}\left(1000^{\circ} \mathrm{k}\right)\end{cases}
$$

The nitric oxide reactions are

$$
\begin{cases}N_{2}+h v \rightarrow N_{2}^{+}+e & k_{p}^{\prime}=3.1 \times 10^{-7} \mathrm{~s}^{-1} \\ N_{2}^{+}+O \rightarrow N O^{+}+N & k_{11}=0.85 \times 10^{-10} \mathrm{~cm}^{3} s^{-1}\left(1000^{\circ} k\right) \\ N O^{+}+e \rightarrow N+O & k_{12}=1.51 \times 10^{-7} \mathrm{~cm}^{3} s^{-1}\left(1000^{\circ} k\right)\end{cases}
$$

Then the ion densities will be computed by:

$$
\begin{aligned}
& n\left(O^{+}\right)=\left(k_{p} / k_{11}\right)\left[n(O) / n\left(O_{2}\right)\right] \\
& n\left(O_{2}^{+}\right)=\left(k_{11} / k_{12}\right)\left[n\left(O^{+}\right) / n_{e}\right] n\left(O_{2}\right) \\
& n\left(N_{2}^{+}\right)=\left(k_{p}^{\prime} / k_{l 1}^{\prime}\right)\left[n\left(N_{2}\right) / n(O)\right] \\
& n\left(N O^{+}\right)=\left(k_{p}^{\prime} / k_{12}^{\prime}\right)\left[n\left(N_{2}^{+}\right) / n_{e}\right] n(O)
\end{aligned}
$$

The Torr et al. (1979) model is valid for daytime hours. To apply it to the nighttime lower ionosphere one should remind that it is maintained due to emitted energy from the terrestrial geocorona at four emission lines: $L_{\alpha}(121.6 \mathrm{~nm})$ and $L_{\beta}(102.6 \mathrm{~nm})$ of the hydrogen atom, the $\mathrm{HeI}$ line $(58.4 \mathrm{~nm})$ of atomic helium, and the $\mathrm{HeII}$ lines $(30.4 \mathrm{~nm}$ ) of singly ionized helium (Strobel et al., 1974, 1980; Kashirin, 1986). The first two lines ionize the lower portion of the range $(100-140 \mathrm{~km})$ and the last two are the driving energy for the upper portion (140-200 km). The produced ionization is proportional to the sum of $I_{\infty}(\lambda) \sigma_{i}(\lambda)$ where $I_{\infty}$ is the energy intensity at wavelength $\lambda$ and $\sigma_{I}$ the ionization cross-section. We estimated first that the energy intensity is $1 / 5$ of the daytime one and the cross section $1 / 20$ of the total daytime amount (see Richards et al., 1994). Hence $k_{p}$ must be multiplied by $10^{-2}$ to get the model valid during nighttime. Applying the model to $160 \mathrm{~km}$ one gets

$$
n\left(O^{+}\right)=1.35 \times 10^{3}, n\left(N_{2}^{+}\right)=57
$$

and taking $n_{e} \sim 5 \times 10^{3} \mathrm{~cm}^{-3}$ (from measurements) results $n\left(O_{2}^{+}\right)=2.2 \times 10^{4} \mathrm{~cm}^{-3}$ and

$$
n\left(\mathrm{NO}^{+}\right)=7.8 \times 10^{4} \mathrm{~cm}^{-3} .
$$

Since these last two values are inconsistent with that of $n_{e}$ three options are possible: a) We underestimate the damping factor in $10^{-2}$;

b) More refined models are required;

c) Transport processes play a definite role in the nighttime ionosphere.

If a damping factor of $10^{-3}$ results from an effective computation the chemical model becomes consistent with Strobel et al. $(1974,1980)$. This is possible since the intensity damping factor of $1 / 50$ seems more reasonable from the works by Torr \& Torr (1985), Tobiska \& Barth (1990) and Tobiska (1991). Still by itself this variation does not fully explain the discrepancies, since the $\mathrm{NO}^{+}$density remains $50 \%$ larger than the electron density. Osterman et al. (1994) limited the total ion production rate to avoid these contradictions. Buonsanto (1990) proposed an alternative model to that employed here but results are not expected to be so much different. Transport processes (Schunk \& Walker, 1973; Lanchester et al., 1989) certainly contribute to the observed discrepancies of the chemistry model. In fact the chemical time constant is $\tau_{\text {che }}=1 / v_{r} \sim 2 \times 10^{3} s$ which is of the same order of the transport timescale (Strobel et al., 1980; Zamlutti, 2003), thus explaining $50 \%$ of the difference. Therefore, the combined action of all these factors is pointed out as the responsible element. 
Transport processes affect the ion density distribution in two aspects:

a) $-\mathbf{u} \cdot \nabla n$, which contributes more with the loss of ionization.

b) $-n \nabla \cdot \mathbf{u}$, which confines or disperses ionization.

Osterman et al. (1994) made their analyses in terms of the amplitude and wavelength of the wind velocity and obtained similar results about the effects of the transport term. Just to give an example from Miller et al. (1993) data at 22.5h LT and $160 \mathrm{~km}$ one gets $\underline{u} \cdot \nabla n \sim 1 \mathrm{~cm}^{-3} \mathrm{~s}^{-1}$ whereas $v_{r} n \sim 10^{-1} \mathrm{~cm}^{-3} \mathrm{~s}^{-1}$, which shows that transport overwhelms local recombination at the considered altitude.

As concerned with the $\nabla \cdot \mathbf{u}$ term Zamlutti (2003) presented the necessary and sufficient conditions for the confinement of ionization applying $(\nabla \cdot \mathbf{u})<0$ to (6). This led two: $(\nabla \cdot \underline{\underline{\gamma}}) \cdot \mathbf{F}+\underline{\underline{\gamma}}: \nabla \mathbf{F}<0$, where the colon denotes the double contraction of two tensors. It was observed, following Zamlutti (1983), that the term $\nabla \cdot \underline{\underline{\gamma}}$ contributes little to the divergence. In fact, if $r$ is much smaller or much larger than unity the components of $\nabla \cdot \gamma$ will have damping magnitudes proportional to $(\nabla r) / r=H^{-1}$, where $H$ is the neutral scale height, as compared to the $\underline{\underline{\gamma}}$ components. Regarding the $\nabla \mathbf{F}$ term the weighting factor will be $2 \pi / \lambda_{z}$ for the components of the neutral drag and dynamo electric field as compared to those of $\mathbf{F}$ components. Using Harper (1977) results the last contribution is comparable to the first at $105 \mathrm{~km}\left(H=7 \mathrm{~km}, \lambda_{z}=45 \mathrm{~km}\right)$ but is twice as large at $130 \mathrm{~km}(H=17 \mathrm{~km})$ and four times larger at $170 \mathrm{~km}(H=31 \mathrm{~km})$. Anyway there is no sign change due to the weighting factors and therefore the divergence becomes negative from the transition in sign of $u_{z}$ at the shear region (see Whitehead, 1989; Lanchester et al., 1989). This transition in sign does not occur at the same height as that of $u_{j z}$ and hence the difference in altitude between the peaks of neutral metal layers and metal ion layers observed in the upper mesospheric region (Alpers et al., 1993; von Zahn \& Hansen, 1988). Osterman et al. (1994) attributed this difference to the vertical phase velocity of the wind.

It must be emphasized that the convergence process is a strictly lower ionosphere event since the $\underline{\underline{\gamma}}$ components, above $140 \mathrm{~km}$, decrease with increasing $H^{-1}$ value. Then $C=-\nabla \cdot \mathbf{u}$ defined as convergence factor has decreasing magnitudes above $140 \mathrm{~km}$ and thicker layers appear at higher heights (see Lanchester et al., 1989). For vertical winds of $30 \mathrm{~m} / \mathrm{s}$ around $140 \mathrm{~km}$ the trapping time scale will be about $20 \mathrm{~min}$. It will increase to one hour for altitudes of $160 \mathrm{~km}$ and $180 \mathrm{~km}$.

A final aspect referred to transport of ionization is the problem of regional circulations of ionization. One is interested in the behavior of the meridional velocity around the equator, which can be described by:

$$
u_{n \theta}=k\left(\mu_{j} v_{j}\right)^{-1} \nabla_{\theta} T(\theta, t)
$$

using the limit of Geisler (1967) results as $\theta \rightarrow 0$. Then a convergent null for $u_{n \theta}$ occurs around $0200 \mathrm{LT}$. It corresponds to a divergent null for $u_{n z}$ since $\nabla \cdot \mathbf{u}_{n}=0$ holds as satisfactory approximation (e.g. Nygrén et al., 1984). If one takes the equatorial vertical divergent node around $100 \mathrm{~km}$ one gets an upward transport of metal species to $140 \mathrm{~km}$ thus establishing a recycling process through a meridional circulation of metal constituents. The cycle includes an upward motion from 100 to $140 \mathrm{~km}$; then a poleward flow of ions around $140 \mathrm{~km}$ which produces an $E_{s}$ layer at some low or middle latitude; this layer presents a systematic downward motion following a convergent null of the wind profile (see Zamlutti, 2003) to $100 \mathrm{~km}$, finally around $100 \mathrm{~km}$ an equatorward flow of metal ions and neutrals completes the cycle. The reader may verify that starting with the convergent null at 0200 LT as above a sporadic layer will appear in the afternoon around $20^{\circ}$ of latitude, since with an upward mean vertical velocity of $5 \mathrm{~m} / \mathrm{s}$ this trip will take around $4 \mathrm{~h}$; then the poleward horizontal flow with meridional velocity of $100 \mathrm{~m} / \mathrm{s}$ expends around $7 \mathrm{~h}$. As this time is larger than the ionization one this process occurs along the path. The systematic downward motion of sporadic E layers, observed at low and middle latitudes, from $140 \mathrm{~km}$ to $100 \mathrm{~km}$ completes the cycle. Other considerations on the equatorial uplift of matter can be found in Dickinson et al. (1975). Carter \& Forbes (1999) employed for neutral metals the transport velocity given by:

$$
\mathbf{u}_{n}=\mathbf{u}_{t}+v^{-1} \mathbf{g}-(D / n) \nabla n
$$

where $\mathbf{u}_{t}$ is the tidal wind velocity, $D$ is the diffusion coefficient and $\mathbf{u}_{n}$ is the actual neutral transport velocity. Since $\mathbf{g}$ and $\nabla n$ have both negative signs they preserve their opposite signs in the equation and balances each other. Hence $\mathbf{u}_{n} \cong \mathbf{u}_{t}$ at lower altitudes (around $100 \mathrm{~km}$ ) as stated in Carter \& Forbes (1999) and employed in our proposed model. Also $\mathbf{u}_{i} \cong \mathbf{u}_{n}$. Though $140 \mathrm{~km}$ is still an intermediate altitude it is a limiting case of the upper approximation of:

$$
\mathbf{u}_{i}=\left[\left(\Omega_{i}^{-1} \mathbf{g}+\mathbf{E} / B\right) \cdot(\mathbf{B} / B)\right] \mathbf{B} / B
$$

(see Carter \& Forbes, 1999; Zamlutti, 2003). This last expression gives rise to the so called fountain effect at the equator (Carter \& 
Forbes, 1999) and explains the poleward $140 \mathrm{~km}$ branch of our meridional circulation model.

\section{SUMMARY AND CONCLUSIONS}

A balance on the major aspects of predicting the occurrence of enhanced ion layers in the low latitude lower ionosphere was done and led to:

a) The ion composition is essentially of molecular $\left(\mathrm{NO}^{+}, \mathrm{O}_{2}^{+}\right)$constituents above $140 \mathrm{~km}$ and metallic species in the range $100-140 \mathrm{~km}$.

b) The availability of metallic ions is a question of meridional circulation, ion lifetime and local transport.

The first problem was addressed using simple chemical and transport considerations. In fact the one order of magnitude increase of chemical results estimates can be easily taken off recalling that the recombination rate is one order of magnitude smaller than the transport term $\underline{u} \cdot \nabla n$, which removes the differences above $140 \mathrm{~km}$.

Near the range 130-140 km charge exchange between molecular ions and metallic neutrals transforms intermediate layers into sporadic metallic layers. The time constant for this process (Murad, 1978) is $10^{4} \mathrm{~s}$, which is compatible with the node descending time of 3-5 hours in the range, $140-120 \mathrm{~km}$ as shown in the data by Mathews (1998).

The availability of metallic species in the range 120-140 km could be explained here to the light of the proposed profile for the density of metallic neutrals, combined with a meridional circulation of these particles. In this case roughly half of available metals around $100 \mathrm{~km}$ are moved up to $120-140 \mathrm{~km}$ at the equator (see Zamlutti, 2003). Compression of the suggested model profile produces metallic ion layers of density $n_{s}=2 \times 10^{4} \mathrm{~cm}^{-3}$, width $\Delta z=0.5 \mathrm{~km}$ for iron (compression factor of 40). Denser layers require more refined models as that of Carter \& Forbes (1999), where the full continuity equation is solved for actual parameters, to be explained. The average or climatological profile proposed here can only be considered for diagnostic purposes in such cases. The metal rapid ionization, combined with the long lifetime suggests the success of the recycling process proposed in Zamlutti (2003) to fill up this gap in the literature (see Wilkinson et al., 1992). The test for consistency performed here agrees with the results from the formal model carried out by Carter \& Forbes (1999).

In a conclusion the chemistry-transport mechanism responsible for the appearance of intermediate layers and their final con- version to metallic sporadic E layers was analyzed using a simple formal model. The results were promising showing its validity. Comparisons with numerical model expectations were also encouraging in a consistency test of the Zamlutti (2003) model.

\section{ACKNOWLEDGEMENT}

The author received a complementary fellowship from Conselho Nacional de Desenvolvimento Científico e Tecnológico under the process 304597/2003-1 (RN).

\section{REFERENCES}

ALPERS M, BLIX T, KIRKWOOD S, KRANKOWSKY D, LÜBKEN FJ, LUTZ S \& VON ZAHN U. 1993. First simultaneous measurements of neutral and ionized iron densities in the upper mesosphere. J. Geophys. Res., 98(A1): 275-283.

BEHNKE RA \& VICKREY JA. 1975. Radar evidence for $F_{e}^{+}$in a sporadicE layer. Radio Science, 10: 325-327.

BRACE LH \& THEIS RF. 1978. An empirical model of the interrelationship of electron temperature and density in the daytime thermosphere at solar minimum. Geophys. Res. Lett., 5: 275-278.

BRISTOW WA \& WATKINS BJ. 1991. Numerical simulation of the formation of thin ionization layers at high latitudes. Geophys. Res. Lett., 18(3): 404-407.

BUONSANTO MJ. 1990. A study of the daytime E-F1 region ionosphere at mid-latitudes. J. Geophys. Res., 95(A6): 7735-7747.

CARTER LN \& FORBES JM. 1999. Global transport and localized layering of metallic ions in the upper atmosphere. Ann. Geophysicae, 17: 190-209.

DICKINSON RE, RIDLEY EC \& ROBLE RG. 1975. Meridional circulation in the thermosphere I. Equinox conditions. J. Atmos. Sci., 32: 17371754.

ECCLES JV \& RAITT WJ. 1992. Reactive collision terms for fluid transport theory. Planet. Space Sci., 40: 47-62.

FORBES JM. 1981. The equatorial electrojet. Rev. Geophys. Space Phys. 19(3): 469-504.

GEISLER JE. 1967. A numerical study of the wind system in the middle thermosphere. J. Atmos. Terr. Phys., 29(3): 1469-1482.

GRANIER C, JEGOU JP \& MEGIE G. 1989. Iron atoms and metallic species in the earth's upper atmosphere. Geophys. Res., 16(3): 243-246.

HARPER RMA. 1977. Comparison of ionospheric currents, magnetic variations, and electric fields at Arecibo. J. Geophys. Res., 82(22): 32333242 
HELMER M, PLANE JMC, QIAN J \& GARDNER CS. 1998. A model of meteoric iron in the upper atmosphere. J. Geophys. Res., 103(D9): 10,91310,926 .

KANE TJ \& GARDNER CS. 1993. Structure and seasonal variability of the nighttime mesospheric Fe layer at midlatitudes. J. Geophys. Res., 98: $16,875-16,886$.

KASHIRIN Al. 1986. Photoionization in the nighttime ionosphere. Geomag. and Aeronomy, 26: 474-478.

KELLEY MC. 1992. The Earth's ionosphere plasma physics and electrodynamics. Academic Press, Inc., New York.

KOPP E. 1997. On the abundance of metal ions in the lower ionosphere. J. Geophys. Res., 102(A5): 9667-9674.

LANCHESTER BS, RISSHBETH H, NYGRÉN T, FALONEN L \& TURUNEN T. 1989. Wave activity, F1-layer disturbance and a sporadic E-layer over EISCAT. J. Atmos. Terr. Phys., 51: 179-196.

MATHEWS JD. 1998. Sporadic E: current views and recent progress. J. Atmos. Solar-Terr. Phys., 60(4): 413-435.

MATHEWS JD \& BEKENY ES. 1979. Upper atmosphere tides and the vertical motion of ionospheric sporadic layers at Arecibo. J. Geophys. Res., 84: 2743-2750.

MATHEWS JD, MACHUGA DW \& ZHOU Q. 2001. Evidence for electrodynamic linkages between spread-F, ion rain, the intermediate layer, and sporadic E: results from observations and simulations. J. Atmos. Solar-Terr. Phys., 63: 1529-1543.

McNEIL JW, LAI ST \& MURAD E. 1996. A model for meteoric magnesium in the ionosphere. J. Geophys. Res., 101: 5251-5259.

MILLER NJ, GREBOWSKY JM \& HEDIN AE. 1993. Equatorial ion composition, 140-200 km, based on atmosphere explorer E data. J. Geophys. Res., 98(A9): 15,685-15,692.

MURAD E. 1978. Problems in the chemistry of metallic species in the Dand E- regions. J. Geophys. Res., 83: 5525-5530.

NAGY AF \& SCHUNK R W. 1987. Ionosphere. Enc. Phys. Sci. Tech., 7: 19-33.

NYGRÉN T, FALONEN L, OKSMAN J \& IUREINENT T. 1984. The role of electric field and neutral wind direction in the formation of sporadic $E$ layers. J. Atmos. Terr. Phys., 46: 373-381.

OSTERMAN GB, HEELIS RA \& BAILEY GJ. 1994. Modeling the formation of intermediate layers at Arecibo latitudes. J. Geophys. Res., 99 (A6): 11,357-11,366.

PLANE JMC \& HELMER M. 1994. Laboratory studies of the chemistry of meteoric metals. Research in Chemical Kinetics, 2: 313-367.

RICHARDS PG, FENNELLY JA \& TORR DG. 1994. EUVAC: a solar EUV flux model for aeronomie calculations. J. Geophys. Res., 99(A5): 89818992.
RISHBETH H \& GARRIOTT OK. 1969. Introduction to ionospheric physics. Academic Press, New York.

SCHUNK RW \& NAGY AF. 2000. Ionospheres, Physics, Plasma Physics, and Chemistry. Cambridge Univ. In Press, N. York.

SCHUNK RW. 1983. The terrestrial ionosphere, Solar-Terrestrial physics (D. Reidel, Dordrecht), 609-676 pp.

SCHUNK RW \& WALKER JCG. 1973. Theoretical ions densities in the lower ionosphere. Planet. Space Sci., 21: 1875-1896.

SCHUNK RW. 1975. Transport equations for aeronomy. Planet. Space Sci., 23: 437-485.

SOJKA JJ. 1989. Global scale, physical models of the F-region i0nosphere. Rev. Geophys., 27: 371-403.

STROBEL DF, YOUNG TR, MEIER RR, COFFEY TP \& ALI AW. 1974. The nighttime ionosphere: E region and lower $F$ region. J. Geophys. Res., 79(22): 3171-3178.

STROBEL DF. 1974. Physics and chemistry of the E region: A review. Radio Science, 9(2): 159-165.

STROBEL DF, OPAL CB \& MEER RR. 1980. Photoionization rates in the night-time E- and F- region ionosphere. Planet. Space Sci., 28(11): 1027-1033.

TOBISKA WK. 1991. Revised solar extreme ultraviolet flux model. J. Atmos. Terr. Phys., 53: 1005-1018.

TOBISKA WK \& BARTH CA. 1990. A solar EUV flux model. J. Geophys. Res., 95(A6): 8243-8251.

TORR DG, TORR MR, BRINTON HC, BRACE LH, SPENCER NW, HEDIN AH, HANON WB, HOFFMAN JH, NIER AO, WALKER JCG \& RUSCH DW. 1979. An experimental and theoretical study of the mean diurnal variation of $\mathrm{O}^{+}, \mathrm{NO}^{+}, \mathrm{O}_{2}^{+}$, and $\mathrm{N}_{2}^{+}$, ions in the mid-latitude F1 layer of the ionosphere. J. Geophys. Res., 84: 3360-3372.

TORR MP \& TORR DG. 1985. Ionization frequencies for solar cycle 21: Revised. J. Geophys. Res., 90: 6675-6678.

VON ZAHN V \& HANSEN TL. 1988. Sudden neutral sodium layers: a strong link a sporadic E layers. J. Atmos. Terr. Phys., 50: 93-104.

WILKINSON PJ, SZUSZCZEWICZEP \& ROBLE RG. 1992. Measurements and modeling of intermediate, descending and sporadic layers in the lower ionosphere: Results and implications for global-scale ionosphericthermospheric studies. Geophys. Res. Lett., 19(2): 95-98.

WHITEHEAD JD. 1989. Recent work on mid-latitude and equatorial sporadic E. J. Atmos. Terr. Phys., 51: 401-424.

ZAMLUTTI CJ. 1975. Atmospheric wave observations at Arecibo. J. Atmos. Terr. Phys., 37: 626-633. 
ZAMLUTTI CJ. 1983. Incoherent scatter observations of mid-latitude sporadic-E and comments on its data analysis. J. Atmos. Terr. Phys., 45: 79-87.

ZAMLUTTI CJ. 1997. On the effects of the reactive terms in the Boltzmann equation. Ann. Geophys., 15: 79-87.
ZAMLUTTI CJ. 1998. On the basic trends of the upper atmosphere modeling: A review. Brazilian J. Geophys., 16(2/3): 159-180.

ZAMLUTTI CJ. 2003. Weather disturbances in the low latitude ionosphere and their low altitude modeling. Workshop IRI, INPE, São José dos Campos, SP, Brazil, june 2001. Adv. Space Res., 31: 597-604.

\section{NOTES ABOUT THE AUTHOR}

Carlos José Zamlutti. Senior Researcher at Instituto Nacional de Pesquisas Espaciais - INPE, since 03/01/1968. Born in Corumbá, MS, Brazil. Graduated (Bs) on Electronic Engineering at Escola Politécnica - Universidade de São Paulo in 1967. Master of Science Degree on Spatial Sciences at Instituto Nacional de Pesquisas Espaciais in 1969. Doctorate in Electrophysics at Cornell University - Ithaca, NY, USA, in 1973. Coordinator of INPE Fortaleza, after training at CNES on Kourou in French Guiana, in 1970. Doctorate data collected at Arecibo Observatory in Puerto Rico, in 1972. Research interest and publications in satellite orbit positioning, collecting and analysis of satellite data, research radars and plasma physics modeling. 